Review

\title{
Functional Polymer Hybrid Nanocomposites Based on Polyolefins: A Review
}

\author{
Sandra Paszkiewicz ${ }^{1, *\left(\mathbb{D}, \text { Krzysztof Pypeć }^{1,2}{ } \text {, Izabela Irska }\right.}{ }^{1}$ (D) and Elzbieta Piesowicz ${ }^{1}$ (i) \\ 1 Department of Materials Technologies, West Pomeranian University of Technology in Szczecin, \\ 70310 Szczecin, Poland; krzysztof.pypec@zut.edu.pl (K.P.); izabela.irska@zut.edu.pl (I.I.); \\ elzbieta.piesowicz@zut.edu.pl (E.P.) \\ 2 Stargum, ul. Cieplna 7, 73110 Stargard, Poland \\ * Correspondence: sandra.paszkiewicz@zut.edu.pl; Tel.: +48-91-449-4589
}

Received: 24 September 2020; Accepted: 12 November 2020; Published: 17 November 2020

\begin{abstract}
For the last twenty years, polymer hybrid nanocomposites have enjoyed unflagging interest from numerous scientific groups and R\&D departments, as they provide notable enhancement of properties, even at low nanofillers' content. Their performance results from many factors, the most important of which is the uniform distribution in the entire volume of the matrix, that still is very challenging, but is the right choice of two types of nanoparticles that can lead to an increase of dispersion stability and even more uniform distribution of fillers. The incorporation of two types of nanofillers, especially when they differ in aspect ratio or chemical nature, allows to additively reduce the price of the final composite by replacing the more expensive filler with the cheaper one, or even synergistically improving the properties, e.g., mechanical, thermal, and barrier, etc., that can extend their usage in the industry. Despite numerous review papers on nanocomposites, there is no review on how the introduction of a hybrid system of nanofillers affects the properties of polyolefins, which are the most commonly used engineering plastics. This review deeply focuses on the structure-properties relationship of polyolefins-based hybrid nanocomposites, especially based on two types of polyethylenes (low-density polyethylenes (LDPE) and high-density polyethylenes (HDPE)) and polypropylene.
\end{abstract}

Keywords: hybrid nanocomposites; polyolefins; low-density polyethylene; high-density polyethylene; polypropylene; functional properties

\section{Introduction}

Polyolefins, especially low- and high- density polyethylenes (LDPE and HDPE, respectively) and isotactic polypropylene (i-PP), can be found as materials that are widely used in products of our daily needs. They belong to a large and extremely popular group (one produced more than 178 million tons in 2015 [1,2]) of plastic materials, due to their exceptional properties, such as low density and water absorption, chemical and corrosion resistance, good electrical insulation, etc. [3]. Thus, they account for over $50 \mathrm{wt} . \%$ of produced polymers [1]. In general, they are polymer hydrocarbons consisting of two basic components: hydrogen and carbon, composed of mixed and connected amorphous and crystalline regions that can be branched into short and long chains [1]. A wide range of physical and physicochemical properties provided by more than 300 grades of commercially available polyolefins ensure their possible applications in many industrial fields, especially in the cables industry, electromechanical, foils, films, containers, packaging, production of pipes, household appliances, and many others [2]. The progress of catalytic processes in polyolefins' manufacturing, in which no solvent is needed, along with their recyclability and the low carbon footprint are the main arguments for the claim that polyolefins can also meet the requirements of sustainable development and green 
polymer chemistry [4-6]. Moreover, their unique properties, and thus their application, can be extended by preparing blends of polyolefins with other polymers [1,3], or by introducing nanoparticles into a polyolefin matrix, and thus obtaining polymer nanocomposites.

For the last thirty years, it is polymer nanocomposites which constitute one of the most evolving cognitive application and research $[7,8]$. They can be received by modifying typically-used polymer matrices by dispersing particles with dimensions of several nanometers. Thus, one can find them as systems composed of two or more phases (continuous and dispersed) with distinct interface surfaces, of which one can characterize the dispersed component by at least one dimension in the nanometric scale. For understanding the relationship between the nanocomposite components, the most interesting research seems to be the interfacial interactions at the nano level [9-11]. Such a great interest in these materials (over 30,000 papers published in 2019 with the keyword "polymer nanocomposites", followed by Science Direct), stems from the fact that the incorporation into the polymer matrix of particles, with at least one dimension not exceeding $100 \mathrm{~nm}$, enables the design and production of materials with extremely high and/or novel properties, with a very small amount of the nanofiller. By mixing the nanofillers with the polymer matrix, the aim is to obtain nanocomposites with the appropriate mechanical, thermal, barrier, magnetic, or biological properties. An explicit improvement in the properties of nanocomposites depends primarily on the dimensions of nanoparticles, the degree of surface development and energy, and the distribution of nanoparticles in the polymer matrix [12]. Materials that differ in terms of their chemical nature (organic and inorganic), physical structure (e.g., amorphous, crystalline), and particle shape (1D-tubular shape, e.g., carbon nanotubes, carbon nanofibers; 2D-lamellar, e.g., graphene derivatives, nanoclays; 3D-"powder-like", e.g., carbon black, mica, etc.) can be used as nanofillers. Carbon nanotubes (CNTs) are found to be one of the most promising 1D-type reinforcing fillers, as they can improve the mechanical, thermal, and electrical properties of the wide range of polymer matrices [13-15]. However, the final properties of polymer/CNT nanocomposites are determined by the type and nature of chemical/physical interactions between the polymer and CNTs [15-18]. More recently, the particular interest of researchers was focused on 1D-type mineral nanoparticles, especially on the ones that can be applied in polyethylene (PE)-based materials intended for the cable industry $[19,20]$. The halloysite nanotubes (HNTs) are an example of this type of mineral nanofiller. The beneficial influence of HNTs on the improvement of polymer properties caused a growing interest in their usage [21]. The morphology of HNTs is similar to multi-walled CNTs (tubular shape and high aspect ratio [22,23]). HNTs are environmentally friendly, naturally occurring, and cheap nanofiller (if compared to multi-walled carbon nanotubes (MWCNTs), $1 \mathrm{~kg}$ of HNTs equals 431.64 USD [24], while MWCNT is ca. 37,600.20 USD [25]). These two types of selected nanotubes also exhibit excellent mechanical properties; the modulus of elasticity of single CNTs is 1-1.7 TPa [26], while the modulus of elasticity of HNTs is $140 \mathrm{GPa}$ (with theoretical values of $230-340 \mathrm{GPa}$ ) [22,27]. However, CNTs also exhibit exceptional thermal conductivity $\left(>3000 \mathrm{~W} \cdot \mathrm{m}^{-1} \cdot \mathrm{K}^{-1}\right)$ and electrical conductivity $\left(10^{5} \mathrm{~S} \cdot \mathrm{m}^{-1}-10^{7} \mathrm{~S} \cdot \mathrm{m}^{-1}\right)$, if compared to the mineral nanotubes. So far, the 2D-type mineral fillers (e.g., clays, natural silicates), unlike 1D-type HNTs, were especially widely used in manufacturing applications, due to their abundance and facile availability. One found that uniformly dispersed nanoclays may also provide a profound variety of advantages (the combination of mechanical, thermal, and barrier properties) to the polymer material [28-30]. However, the discovery of the other two-dimensional platelet nanofiller, namely graphene, due to its intriguing properties including high electrons' mobility at room temperature [31,32], exceptional thermal conductivity $\left(5000 \mathrm{~W} \cdot \mathrm{m}^{-1} \cdot \mathrm{K}^{-1}\right.$ [33]), extremely high surface area (the theoretical limit of $2630 \mathrm{~m}^{2} \cdot \mathrm{g}$ ), gas impermeability, and superior mechanical properties (Young's modulus of $1 \mathrm{TPa}$ and ultimate strength of $130 \mathrm{GPa}$ ) [34] attracted much attention on nanocomposites with its content. Finally, the three-dimensional (3D) nanofillers, which are relatively equiaxed particles having all three dimensions in the nanoscopic scale and are usually in spherical and cubical shapes, are widely applied to improve the functional properties of polymer materials [35]. Examples of 3D-type nanofillers, which are commonly called nanospheres, nanogranules, etc., include nanosilica, 
nano-titanium oxide, polyhedral oligomeric silsesquioxane (POSS), nanomagnesium hydroxide, semiconductor carbon black (CB), silica, and many more [12,36]. For instance, for many years, carbon black (CB) has been used as an inexpensive filler for thermoplastic and rubber materials in electrically conductive applications [37]. However, the amount of CB which is required to observe the changes in properties, such as electrical conductivity, is that high (even more than $10 \mathrm{wt} . \%$ ) that it might cause the deterioration of the other properties of the final material, such as processability, gloss, and mechanical properties [37-39]. Therefore, one combined 3D-type nanofillers, such as CB, talc, mica, etc., with other types of nanofillers to obtain the improvement in properties at the lowest possible loading. The polymer hybrid nanocomposites containing at least two types of nanofillers, that differ in shape, are becoming more and more popular in the scientific community, especially in the case of improving mechanical, barrier, and thermal properties, and obtaining electrical conduction paths with the lowest possible concentration of both nanofillers (Figure 1). This article is a review of the literature, and presents the results of our own research on the preparation of polymer hybrid nanocomposites and the observation of the so-called synergistic effect of improving functional properties. The presented discussion of the results may make it easier for other researchers who wish to expand application possibilities of polymer nanocomposites based on a hybrid system of nanofillers in polymer matrices, which are polyolefins.

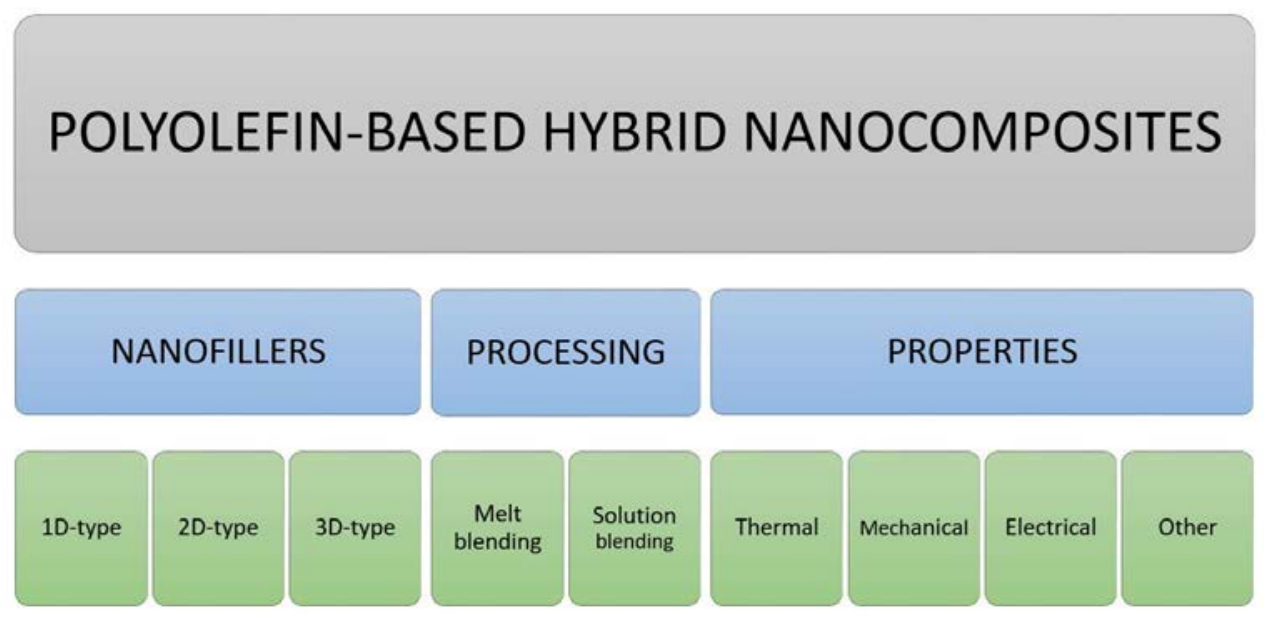

Figure 1. Schematic illustration summarizing the main assumption of the review on polyolefins' hybrid nanocomposites.

\section{Processing}

Polymer hybrid nanocomposites, or, generally, polymer nanocomposites, can be manufactured by three main methods: in situ polymerization, solution, and melt blending [40]. One selects the appropriate method according to the type of polymer matrix, nanofiller, or the system of nanofillers, and awaited characteristics for the final products. However, hybrid nanocomposites based on polyolefin matrices are prepared by only two of the aforementioned methods, employing solution and melt blending, of which, however, the vast majority is obtained according to the latter method. In the present review, the selected LDPE-, HDPE-, and PP-based hybrid nanocomposites have been prepared by these methods, basically owing to their simplicity. However, in the case of melt and solution blending techniques, because of the difficulties in achieving proper dispersion of nanofillers, in the present review one presents the modifications of these methods.

\subsection{Solution Blending}

The solution blending technique allows to easily disperse nanofiller (or the hybrid system of nanofillers) in the appropriate solvent selected for the polymer (Figure 2) [40,41]. Several dispersing ways can be used to distribute the nanofiller/nanofillers in the polymer matrix, utilizing ultrasonic 
irradiation, magnetic stirring, or even shear mixing [42]. In this method, when the solvent evaporates, several problems arise, from the economic and environmental points of view. Generally, the main limitations are the possible agglomerations and aggregation of nanoparticles and environmental constraints $[37,43,44]$. Therefore, this technique is rather limited to polymers that are soluble in water [37], however, there are few studies on applying these techniques to obtain polyolefin-based nanocomposites. For instance, Deka and Maji [45] prepared wood polymer composites (WPC) based on, among others, HDPE, LDPE, and PP, with Phragmites karka wood flour (WF), polyethylene-co-glycidyl methacrylate (PE-co-GMA), and further modified with nanoclay and $\mathrm{TiO}_{2}$ by solution technique. The same authors [46] also checked the influence of clay and $\mathrm{SiO}_{2}$ in the same system of WPC based on either HDPE, LDPE, or PP, containing WF, and PE-co-GMA. In turn, Li et al. [47] prepared HDPE-based hybrid nanocomposites containing graphite nanofibers (GNF) and carbon black (CB), via a two-stage process consisting of preparation of masterbatch of HDPE/GNF by solution mixing using xylene as the solvent, and, subsequently, by melt mixing with CB. Also, Lee et al. [48] investigated the effects of the addition of MWCNTs on the positive temperature coefficient (PTC) characteristics of conventional $\mathrm{CB} / \mathrm{HDPE}$ composites by the combined solution and melt-mixing process.

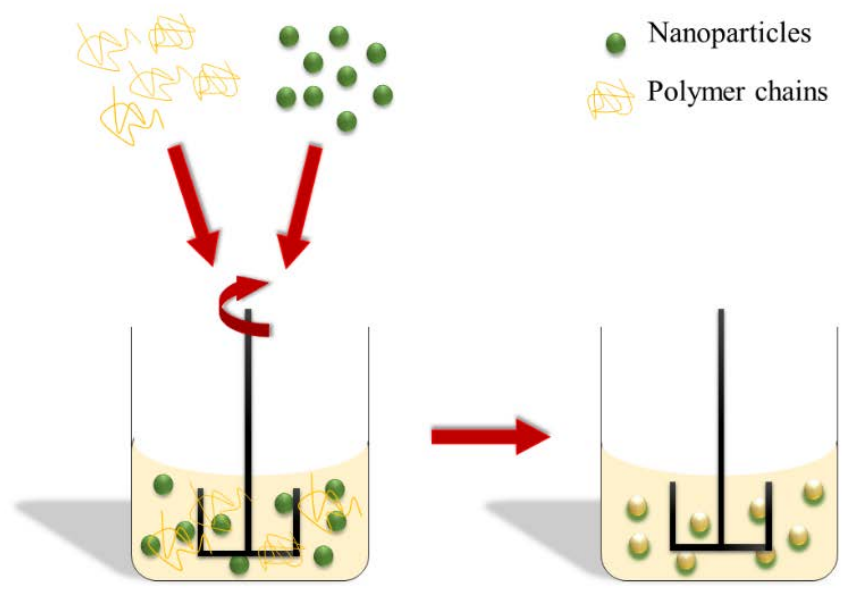

Figure 2. Schematic illustration for the solution blending method.

\subsection{Melt Blending}

The second blending technique is melt blending, where the nanofillers are directly mixed with the polymer in the molten state (Figure 3). The molecular mass and mass distribution are the two main polymer features, on which depend the strain that is applied on the nanoparticles during mixing in the molten state [49]. So, in the beginning, large agglomerates and aggregates are being crushed, and form smaller systems dispersed randomly in the whole volume of the polymer matrix. Subsequently, the "second" step, which primarily depends on time and the interfacial interactions between the polymer and the surface of the nanoparticles, ensues [44,50]. In this stage, the transfer of strain from the polymer to these smaller agglomerations of nanoparticles leads to stronger shearing, which further breaks them into individual particles [40]. For melt blending, one can apply both single- and twin-screw extruders [35], however, to obtain the high-quality dispersion of nanoparticles, the intermeshing co-rotating twin-screw extruders constitute the best choice. However, there are still several parameters that are difficult to control, such as the polymer-nanoparticle interactions and the processing conditions (temperature and residence time), which shows some disadvantages of melt blending [40]. Nevertheless, the most crucial advantages of melt blending are (i) the fact that it can be well-matched with several industrial processes (extrusion and injection molding), and thus, it can be easily commercialized [49], and (ii) the enhancement of heat stability [51], improvement of mechanical properties [52-55], and low cost-effectiveness and eco-friendliness (do not use solvent) [40]; whereas substantial limitation poses high temperatures that can damage the modified surface of the nanofillers [56]. 


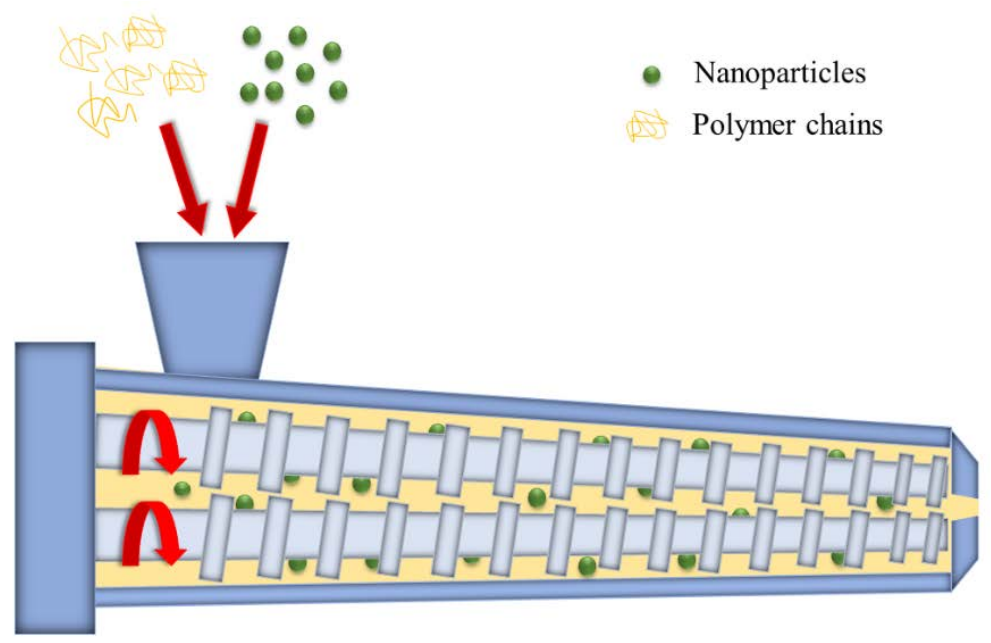

Figure 3. Schematic illustration for the melt blending method.

One can use the melt blending technique to produce polymer nanocomposites based on different types of matrices: ethylene-vinyl acetate (EVA) [57,58], poly(vinyl chloride) (PVC) [59], polycarbonate (PC) [60], and polyamide 6 (PA6) [61], but foremostly polyolefins [52-54,62], etc. However, herein, one focuses mainly on the LDPE, HDPE, and PP- based hybrid nanocomposites prepared by melt blending. For instance, Zagho et al. [63] prepared LDPE-based nanocomposite using the melt mixing technique, followed by compression molding, to analyze the influence of titanium oxide nanoparticles (TONPs) and/or MWCNTs on the thermal properties. They also further expanded their study [34] by exposing the samples to $\gamma$-irradiation. In turn, in our previous studies on LDPE-based hybrid nanocomposites [62,64], we compared the incorporation of single nanofillers, such as MWCNTs or CB, to the hybrid MWCNTs+graphene nanoplatelets (GNPs) or MWCNTs+CB, and checked if the positive hybrid effects can be visible in both improvement of tensile strength and electrical and thermal conductivity when a combination of $1 \mathrm{D}$ and 2D, or 1D and 3D, nanofillers are applied. Similarly, Badgayan et al. [65] prepared HDPE-based hybrid nanocomposites containing MWCNTs (1D-type) and h-boron nitride nanoplatelets-(h-BNNPs) (2D-type), and investigated their effect on the selected properties of the materials. Meanwhile, Mekhzoum et al. [66] manufactured PP-based hybrid nanocomposites using melt compounding with different Moroccan montmorillonite (MMT):graphene nanosheets (GNs) ratio, and total loading of $3 \mathrm{wt} . \%$. Additionally, Franciszczak et al. [67] investigated the melt blended hybrid bio-nanocomposites based on PP with halloysite nanotubes (HNTs) and kenaf fibers.

\section{Properties}

The introduction of a hybrid system of nanofillers into the polymer matrix, depending on their type, is intended to provide the nanocomposites with appropriate mechanical, thermal, optical, barrier, or biological properties. A significant enhancement in the properties of polymer nanocomposites results primarily from the size and shape of nanofiller particles, specific surface area, surface development, surface energy, and the distribution of nanoparticles in the polymer matrix. As already mentioned, the most important advantages of polymer nanocomposites include increased stiffness (without loss of impact strength), increased thermal and dimensional stability, increased resistance to fire, improved barrier effect, good optical properties, and-in the case of the incorporation of conductive carbon nanofillers (such as CNTs, graphene derivatives forms, carbon black, etc.)—additional electrical and thermal conductivity. In addition to the above-mentioned advantages, nanocomposites have certain disadvantages, which include a high price and difficulties in obtaining a high and uniform dispersion of nanofillers in the polymer. The evident improvement of polymer nanocomposites' properties resulted from the synergy of nanofillers interactions on the polymer matrix makes it interesting to study the 
properties of polymer hybrid nanocomposites. Based on the above-mentioned principles, this study pursues a review of LDPE, HDPE, and PP-based hybrid nanocomposites with different types of fillers.

\subsection{Mechanical Properties}

In general, the mechanical properties of a polymer hybrid nanocomposite strongly depend on the particles' size, quality of the dispersion, interfacial interactions, and nanoparticles' concentration $[8,26,40]$. The usage of the two, or even three, types of nanofillers as a hybrid system (organic and/or inorganic) with excellent mechanical properties, along with the understanding of their chemistry and intrinsic properties, led to developing new polymer hybrid nanocomposites with improved properties, resulting from the law of mixture or the so-called positive hybrid effect. Among others, Zagho et al. [34] investigated the influence of Y-irradiation on the mechanical properties of titanium oxide nanoparticles $\left(\mathrm{TiO}_{2} \mathrm{NPs}\right) / \mathrm{MWCNTs}$ hybrid LDPE-based nanocomposites. This group prepared LDPE hybrid nanocomposite using the melt mixing technique, and then exposed the samples to different doses of Y-radiation ( 5 to $50 \mathrm{kGy}$ ). They observed that the tensile strength initially decreased after $\mathrm{TiO}_{2} \mathrm{NP}$ or MWCNT addition, but subsequently increased along with a further increase in the MWCNTs content. Besides this, they observed the effect of the exposure to a dosage of 5 and $25 \mathrm{kGy}$ of Y-radiation on the tensile strength of nanocomposites. They observed that the exposure to a dosage of Y-radiation caused a decrease of tensile characteristics (elongation at break and Young's modulus) of the composites. Besides this, Deka et al. $[45,46]$ studied how the incorporation of $\mathrm{SiO}_{2}$ or $\mathrm{TiO}_{2}$, along with nanoclay, can improve the mechanical properties of WPC, based on polyolefins. The properties of WPC were improved after the incorporation of a hybrid system of nanofillers $\mathrm{SiO}_{2}$ /nanoclay [46] or $\mathrm{TiO}_{2} /$ nanoclay [45] resulted from binding the polymer chains inside the spaces between galleries and thus restricting the mobility of the polymer chains at the same time. Whereas, Sanchez-Valdez [68], using HDPE/EPDM-g-MA/Ag/clay hybrid nanocomposites, observed that only clay acts as the reinforcing agent, so the materials without clay, or only with silver, exhibited a reduction in modulus and tensile strength. In our previous study on LDPE-based hybrid nanocomposites [62,64], the noticeable improvement in mechanical properties was visible, especially for hybrids of MWCNTs/GNPs and MWCNTs/nanosized carbon black (nCB), in comparison to nanocomposites containing only MWCNTs, GNPs, or nCB. It was found that MWCNTs in both of these systems were more promising as reinforcing agents. Similarly to us, Dabees et al. [69] also observed, in $\mathrm{HDPE} / \mathrm{MWCNTs} / \mathrm{Al}_{2} \mathrm{O}_{3}$ hybrid nanocomposites, that the incorporation of MWCNTs caused strong improvement of mechanical properties. However, after optimization of the material ratios, it was found that hybrid composite with $2.4 \% \mathrm{Al}_{2} \mathrm{O}_{3}$ and $0.6 \%$ MWCNTs exhibited enhanced mechanical properties, compared to other ratios ( $3 \%$ MWCNTs and 5\% MWCNTs). It is also worth mentioning the research of Aguilar et al. [70], who, in PP-based hybrid nanocomposites with organically modified montmorillonite (oMMT) and different types of calcium carbonates $\left(\mathrm{CaCO}_{3}\right)(\mathrm{CC})$ prepared by melt blending, observed a synergistic improvement effect, in particular when biomineralized calcium carbonate (MCC) was applied. Much higher tensile modulus and yield stresses were obtained when MCC particles were incorporated into PP/oMMT composite. The reinforcing mechanism was assigned to the synergy between oMMT and $\mathrm{CaCO}_{3}$, especially in the presence of MCC with higher surface area and lower pore size if compared to the commercial $\mathrm{CaCO}_{3}$ particles. Besides, Mekhzoum et al. [66], in PP/Moroccan montmorillonite (MMT)/graphene nanosheets (GNs) hybrid nanocomposites, also observed the positive hybrid effect in improving the mechanical properties of the final material. They proved that the 1.5:1.5 hybrid nanocomposite exhibited a good compromise between stiffness and ductility (a 68\% improvement in Young's modulus compared to neat PP). In turn, Pandey et al. [71] also observed the increase in mechanical performance (tensile strength, tensile modulus, and impact strength) of PP/MWCNTs/clay hybrid nanocomposites, but it was not that significant (about $24 \%$ improvement in tensile strength). They explained this phenomenon with a more intact 3D network achieved by clay-clay, clay-MWCNTs, and clay-polymer-MWCNTs interactions, resulting in disruption of the layered silicates in the network created by MWCNT, thus forming the islands isolated by clay platelets. 
In turn, Mohammadi and Moghbeli [72], who incorporated organically modified nanofillers (mica and clay) into semicrystalline PP, also observed the improvement in tensile properties, but it was strongly dependent on the nanoparticles' content and their distribution in the matrix. However, despite no significant improvement in tensile characteristics observed, the improvement in fracture toughness was meaningful. Furthermore, in quite similar systems based on PP and MMT, but with rice husk (RH), Majeed et al. [73] observed the improvement in tensile and flexural modulus, and explained it as the presence of stiffer, delaminated platelets with high aspect, which resulted in stronger interactions of MMT with PP chains. Moreover, they claimed that this improvement in mechanical properties was due to the incorporation of MMT to the $\mathrm{PP} / \mathrm{RH}$ system, and was stronger in the presence of the PP-g-MAH compatibilizer. Furthermore, the work of Rahman et al. [74] is also worth mentioning, who prepared jute fiber/PE bio-composites, and subsequently reinforced these biocomposites with $\mathrm{SiO}_{2}$ and nanoclay. They noticed a significant increase of tensile strength resulting from the addition of silica and clay, that, at the same time, enhanced the compatibility between fiber and matrix. In our recent study on bio-nanocomposites based on PP containing HNT and kenaf fibers [67], we observed that Young's modulus and strength were improved along with the addition of low content of HNTs. Moreover, the gain of Notched Izod impact strength, obtained by the incorporation of short kenaf fibers, was maintained in hybrids with low concentrations of HNTs (Figure 4).

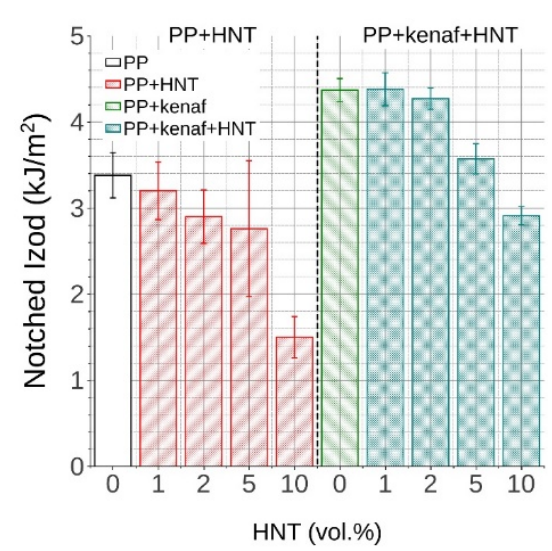

Figure 4. Izod impact strength of polypropylene (PP)-based bio-nanocomposites with different volumetric contents of halloysite nanotubes (HNTs) [67].

\subsection{Thermal Properties}

Nanoparticles, in general, both organic and inorganic, strongly affect the thermal properties of polymer matrices [40]. Especially, carbon nanofillers (CNTs, graphene derivatives) are found to act as highly effective nucleating agents that can meaningfully speed up the crystallization kinetics and/or induce exceptional crystalline morphologies in nanocomposites [75]. Moreover, the thermal stability can be strongly improved by the incorporation of nanofillers, which can "deactivate" the free radicals, and thus shift the thermal decomposition temperatures toward higher values. Herein, one focuses on the effect of the hybrid system of nanoparticles on the improvement of the thermal properties of polyolefin-based nanocomposites. For instance, Zagho et al. [63] investigated the effect of the hybrid system of titanium oxide nanoparticles (TONPs) and/or MWCNTs on the thermal stability LDPE. They found that the introduction of TONPs did not modify the value of crystallization temperature $\left(\mathrm{T}_{\mathrm{c}}\right)$, only that the addition of the hybrid system of filler changed the value of $\mathrm{T}_{\mathrm{c}}$. In turn, the melting temperature $\left(\mathrm{T}_{\mathrm{m}}\right)$ has not been changed at all in the analyzed systems. Moreover, they observed the improvement in thermal stability after incorporating MWCNTs and hybrid system MWCNTs/TONP, if compared when TONP was incorporated, while, in HDPE/EPDM-g-MA/Ag/clay hybrid nanocomposites [68], the noticeable thermal stability improvement was observed after the inclusion of both clay and silver. We have similar observations in LDPE/MWCNTs/GNP [62] and LDPE/MWCNT/nCB [64] hybrid nanocomposites, where the incorporation of carbon nanoparticles 
improved thermo-oxidative stability of the LDPE matrix. The most significant improvement was observed for the masterbatches (at the highest concentration of nanofillers, i.e., $20 \mathrm{wt} . \%$ ). However, for both series of hybrid nanocomposites at both ratios of 3:1 and 1:1, at the content of $3 \mathrm{wt} . \%$ of nanofillers one was already allowed to observe the improvement of thermo-oxidative stability. Thus, when comparing nanotubes with nanoplatelets and powder-like nanoparticles at the same content, it can be concluded that the strongest improvement on the thermo-oxidative stability was observed when MWCNTs were added. Unfortunately, the mixture of MWCNTs and GNPs, or MWCNTs with $\mathrm{nCB}$, did not provide a synergistic effect. Furthermore, the incorporation of these three types of nanofillers (MWCNTs, GNP, nCB) and their hybrid systems also did not affect crystallization and melting temperatures, and the values of degree of crystallinity. However, in PP-based hybrid nanocomposites containing MWCNTs and clay, Pandey et al. [71] revealed that both nanofillers caused the nucleation effect on the matrix. Moreover, they observed an explicit improvement in thermal stability of PP matrix (an increase of $82{ }^{\circ} \mathrm{C}$ in the onset degradation temperature for the hybrid composites), which was explained by the existence of two types of mechanism: (1) few MWCNTs acted as the bridges and connected the spaces between clay layers; and (2) the remaining MWCNTs got interposed between clay layers and formed a sandwich structure, leading to intercalation of clay layers. Majeed et al. [73] observed in PP/MMT/RH composites that the addition of RH caused the decrease of thermal stability of PP; however, the incorporation of MMT to the PP/RH system contributed to the improvement of the thermal stability of hybrid nanocomposite. In addition, in PP-based ternary systems containing organically modified-grafted mica (OMGM) and organically modified montmorillonite (OMMT), a strong nucleating behavior of nanofillers on PP-matrix was also visible [72]. Moreover, authors attributed the increase in the $T_{m}$ to the effect of OMGM that were able to produce more perfect crystals and form lamellas with higher thicknesses, while the lowering of the value of $T_{m}$ at the higher nanoparticles' content resulted probably from a considerable decrease in the thickness of the lamellas and size of the spherulites.

\subsection{Electrical Conductivity}

Electrical conductivity is an important feature resulting from the incorporation of conducting nanofillers, such as CNTs, graphene derivatives, carbon black, etc., into the insulating polymer material. The conductivity of polymer nanocomposites results from several factors, among others the proper dispersion, nanofillers' concentration, and their conductivity, and foremost the electrical resistance at the interface. In our study on LDPE/MWCNT+GNP hybrid nanocomposites [62], an explicit increase in electrical conductivity was observed at the content of only $1.5 \mathrm{wt} . \%$ of MWCNTs (percolation threshold $\varphi_{\mathrm{c}}$ ) (Figure 5a). Moreover, nanocomposites with MWCNTs exhibited higher electrical conductivity in comparison to nanocomposites with GNPs at the same nanofiller content, implying that MWCNTs were more efficient in improving the conductivity (Figure 5a). The dilutions of the masterbatch that contained $20 \mathrm{wt} . \%$ of nanofillers (MWCNTs+GNPs) to $5 \mathrm{wt} . \%$, and even $3 \mathrm{wt} . \%$, reveal that when, in the hybrid of MWCNTs+GNPs, the ratio was 3:1, higher values of electrical conductivities were visible, in comparison to the series with the ratio of 1:1. Similarly, in the study on LDPE-based nanocomposites containing MWCNTs, but where we replaced GNPs by 3D nanosized carbon black (nCB) [64], we observed that the introduction of nCB into LDPE did not significantly affect the electrical conductivity (Figure $5 b$ ). Only for the masterbatch with $20 \mathrm{wt} . \%$ of nCB was it possible to observe the increase in electrical conductivity for about six orders of magnitude. Based on the results of electrical conductivity, one can conclude that MWCNTs were the most efficient conductive nanofiller, in comparison to GNPs and $\mathrm{nCB}$, since nanocomposites containing MWCNTs exhibited the highest values of conductivity in the aforementioned systems (LDPE/GNP, LDPE/nCB, and LDPE with a hybrid system of MWCNTs+GNP, or MWCNTs+nCB) (Figure 5). This is due to the fact that the value of the electrical percolation threshold in polymer nanocomposites is strongly affected by the geometry of the filler, and the ones with elongated geometry (1D-type, such as nanotubes, nanofibers, etc.) can be used to achieve a relatively low value of $\varphi_{\mathrm{c}}$. Generally, the electrical percolation threshold 
is achieved by conventional, micrometer-scale conductive fillers, such as $\mathrm{CB}$, exfoliated graphite, etc., at the concentration of $10-50 \mathrm{wt} . \%$, which results in deterioration of mechanical properties and higher density [64].

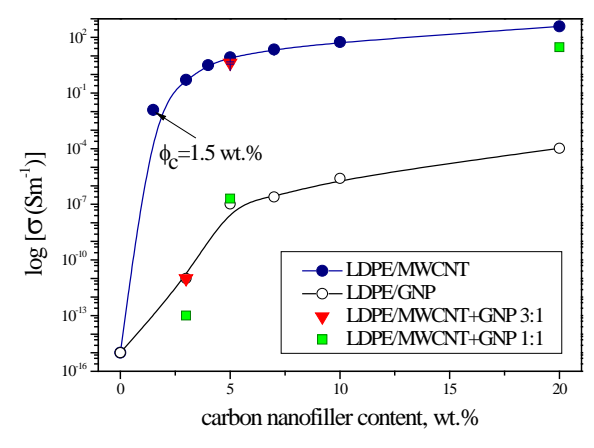

(a)

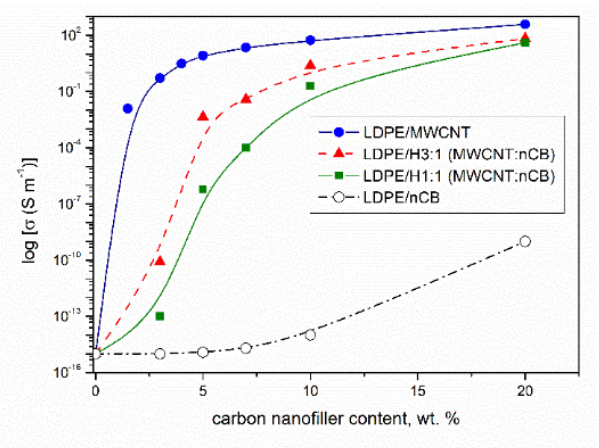

(b)

Figure 5. The electrical conductivity vs. nanofiller content (wt.\%) of the series of low-density polyethylenes (LDPE)/MWCNTs+graphene nanoplatelets (GNPs) (a) [62], and the series of LDPE/MWCNTs+nanosized carbon black (nCB) hybrid nanocomposites (b) [64].

\subsection{Other Functional Properties}

The hybrid nanofillers' system can also affect the other properties of polyolefin-based nanocomposites. For instance, by incorporating silver $(\mathrm{Ag})$, which exhibits renowned antimicrobial activity against most of the bacteria (both gram-positive and gram-negative), fungi, protozoa, and certain types of viruses, one can endow polyolefins with antimicrobial properties [76]. Sanchez-Valdes [68] analyzed the ability of a maleated elastomer to act as a compatibilizer that allows better exfoliation and dispersion of clay and silver nanoparticles. Moreover, he studied its effect on mechanical (both stiffness and toughness) and antimicrobial properties in HDPE/clay/silver nanocomposite. Deka et al. [45] confirmed that the incorporation of $\mathrm{TiO}_{2}$ into the WPC caused an increase in UV stability, while the incorporation of a hybrid system of nanoclay/ $/ \mathrm{TiO}_{2}$ caused the improvement of the flame retardancy and a decrease in the water absorption capacity (WAC) of WPC; whereas Badgayan et al. [77] proved that HDPE/MWCNTs/h-boron nitride nanoplatelets (BNNP) hybrid nanocomposites exhibited superior wear properties, optimum surface, and thermal expansion properties. They claim that these hybrid composites, with improved mechanical properties along with superior wear resistance, could enhance the range of polymer nanocomposites in low load-bearing applications.

\section{Conclusions and Future Perspectives}

Although meaningful progress has been achieved in the polyolefin hybrid nanocomposites with different nanofillers, there are many issues to be investigated: (i) the improvement in mechanical properties, without deteriorating other features; (ii) interactions of nanofillers differing in shape; (iii) creation of conducting paths benefiting from positive hybrid effect; and (iv) improvement of thermal and thermo-oxidative stability if compared to the neat polymer. The challenge is to make further development of hybrid nanocomposites, due to the lack of simple models linking the structure of the final materials with its performance characteristics. Despite this, many papers have been already published on polyolefins-hybrid nanocomposites containing different types of nanofillers; this review revealed many limitations of these materials, mainly because the improvement of properties most often results from the law of mixtures, and not, as expected, from the so-called positive hybrid effect (synergism of properties). Moreover, unfortunately, in the analyzed systems, it is most often the "more expensive" fillers, e.g., MWCNT, Ag, etc., that provide functional properties with a relatively lower concentration, and, thus, less impact on the deterioration of processing. Therefore, understanding the mechanisms behind the improved properties resulting from improved dispersion and interactions at 
the filler-filler and nanofiller-polymer interfaces will make it practicable to obtain polymer hybrid nanocomposites with improved properties, and, at the same time, the lowest possible nanofillers' content. Moreover, polyolefins are one of the most commonly used polymer materials, so introducing the smallest possible amount of modifying agents will not affect the recycling of these nanocomposites. It is obvious that in the years to come, bio-polyolefins (based on renewable raw materials) should replace those of petrochemical origin. In the opinion of the authors of this review paper, the incorporation of the so-called "green" fillers, such as clays, kenaf fibers, HNTs, rice husk, etc., is also an important alternative in reinforcing the strategy of polyolefin-based hybrid nanocomposites. These new functional hybrid materials based on polyolefins, due to the simplicity of their preparation and the possibility of transferring them to industrial grades, enable their use (depending on the type of filler system used), among others, in the cable industry (conductive compounds), automotive industry (bumpers, holders, racks), the food industry, and many others. Therefore, it is of extreme importance to continue to work on hybrid nanofillers systems, which will enable the production of novel functional polyolefin-based nanocomposites.

Author Contributions: Writing-original draft preparation: S.P.; writing-review and editing: I.I.; project administration: E.P. and K.P. All authors have read and agreed to the published version of the manuscript.

Funding: This research was founded by TELE-FONIKA Kable S.A., project number POIR.01.01.01-00-0148/17 granted by the National Centre for Research and Development in Warsaw, Poland under the Operational Program Intelligent Development.

Conflicts of Interest: The authors declare no conflict of interest.

\section{References}

1. Sauter, D.W.; Taoufik, M.; Clement, A. Polyolefins, a Success Story. Polymers 2017, 9, 185. [CrossRef] [PubMed]

2. AlMa'adeed, M.A.-A.; Krupa, I. Introduction. In Polyolefin Compounds and Materials; International Publishing: Berlin/Heidelberg, Germany, 2016; pp. 1-11.

3. Vasile, C. Handbook of Polyolefins, 2nd ed.; Marcel Dekker Inc.: Basel, Switzerland, 2000.

4. Stürzel, M.; Mihan, S.; Mülhaupt, R. From Multisite Polymerization Catalysis to Sustainable Materials and All-Polyolefin Composites. Chem. Rev. 2016, 116, 1398-1433. [CrossRef] [PubMed]

5. Anastas, P.T.; Warner, J.C. Green Chemistry: Theory and Practice; Oxford University Press: Oxford, UK, 1998.

6. Mülhaupt, R. Green Polymer Chemistry and Bio-based Plastics: Dreams and Reality. Macromol. Chem. Phys. 2012, 214, 159-174. [CrossRef]

7. Hussain, F.; Hojjati, M.; Okamoto, M.; Gorga, R.E. Review article: Polymer-matrix Nanocomposites, Processing, Manufacturing, and Application: An Overview. J. Compos. Mater. 2006, 40, 1511-1575. [CrossRef]

8. Omanović-Mikličanin, E.; Badnjević, A.; Kazlagić, A.; Hajlovac, M. Nanocomposites: A brief review. Health Technol. 2020, 10, 51-59. [CrossRef]

9. Chen, J.; Liu, B.; Gao, X.; Xu, D. A review of the interfacial characteristics of polymer nanocomposites containing carbon nanotubes. RSC Adv. 2018, 8, 28048-28085. [CrossRef]

10. Rittigstein, P.; Torkelson, J.M. Polymer-nanoparticle interfacial interactions in polymer nanocomposites: Confinement effects on glass transition temperature and suppression of physical aging. J. Polym. Sci. Part. B: Polym. Phys. 2006, 44, 2935-2943. [CrossRef]

11. Kumar, D.P. Optimization of Interfacial Interactions to Achieve Nanoscale Dispersion of Clay in Polymer/Clay Nanocomposites. Ph.D. Thesis, University of Tennessee, Knoxville, TN, USA, 2007.

12. Roslaniec, Z.; Krolikowski, W. Polymer nanocomposites. Kompozyty 2004, 4, 3-16.

13. Thostenson, E.T.; Li, C.; Chou, T.-W. Nanocomposites in context. Compos. Sci. Technol. 2005, 65, 491-516. [CrossRef]

14. Moniruzzaman, M.; Winey, K.I. Polymer Nanocomposites Containing Carbon Nanotubes. Macromolecules 2006, 39, 5194-5205. [CrossRef]

15. Spitalsky, Z.; Tasis, D.; Papagelis, K.; Galiotis, C. Carbon nanotube-polymer composites: Chemistry, processing, mechanical and electrical properties. Prog. Polym. Sci. 2010, 35, 357-401. [CrossRef] 
16. Sahoo, N.G.; Rana, S.; Cho, J.W.; Li, L.; Chan, S.H. Polymer nanocomposites based on functionalized carbon nanotubes. Prog. Polym. Sci. 2010, 35, 837-867. [CrossRef]

17. Ma, P.-C.; Siddiqui, N.A.; Marom, G.; Kim, J.-K. Dispersion and functionalization of carbon nanotubes for polymer-based nanocomposites: A review. Compos. Part. A Appl. Sci. Manuf. 2010, 41, 1345-1367. [CrossRef]

18. Coleman, J.N.; Khan, U.; Blau, W.J.; Gun'Ko, Y.K. Small but strong: A review of the mechanical properties of carbon nanotube-polymer composites. Carbon 2006, 44, 1624-1652. [CrossRef]

19. Burzynski, M.; Paszkiewicz, S.; Piesowicz, E.; Irska, I.; Dydek, K.; Boczkowska, A.; Wysocki, S.; Sieminski, J. Comparison study of the influence of carbon and halloysite nanotubes on the preparation and rheological behavior of linear low density polyethylene. Polimers 2020, 65, 95-98. [CrossRef]

20. Polanský, R.; Kadlec, P.; Slepička, P.; Kolská, Z.; Švorčík, V. Testing the applicability of LDPE/HNT composites for cable core insulation. Polym. Test. 2019, 78, 78. [CrossRef]

21. Szpilska, K.; Czaja, K.; Kudla, S. Halloysite nanotubes as polyolefin fillers. Polimers 2015, 60, 359-371. [CrossRef]

22. Rooj, S.; Das, A.; Heinrich, G. Tube-like natural halloysite/fluoroelastomer nanocomposites with simultaneous enhanced mechanical, dynamic mechanical and thermal properties. Eur. Polym. J. 2011, 47, 1746-1755. [CrossRef]

23. Esawi, A.; Morsi, K.; Sayed, A.; Taher, M.; Lanka, S. The influence of carbon nanotube (CNT) morphology and diameter on the processing and properties of CNT-reinforced aluminium composites. Compos. Part. A Appl. Sci. Manuf. 2011, 42, 234-243. [CrossRef]

24. Chemistry. Available online: https://www.sigmaaldrich.com (accessed on 7 September 2020).

25. NC7000 ${ }^{\mathrm{TM}}$. Industrial Multiwall Carbon Nanotubes. Available online: https://www.nanocyl.com/product/nc7000/ (accessed on 7 September 2020).

26. Li, Y.; Huang, X.; Zeng, L.; Li, R.; Tian, H.; Fu, X.; Wang, Y.; Zhong, W.-H. A review of the electrical and mechanical properties of carbon nanofiller-reinforced polymer composites. J. Mater. Sci. 2018, 54, 1036-1076. [CrossRef]

27. Ng, K.-M.; Lau, Y.-T.R.; Chan, C.-M.; Weng, L.-T.; Wu, J. Surface studies of halloysite nanotubes by XPS and ToF-SIMS. Surf. Interface Anal. 2011, 43, 795-802. [CrossRef]

28. Maiti, P.; Nam, P.H.; Okamoto, M.; Hasegawa, N.; Usuki, A. Influence of Crystallization on Intercalation, Morphology, and Mechanical Properties of Polypropylene/Clay Nanocomposites. Macromolecules 2002, 35, 2042-2049. [CrossRef]

29. Yano, K.; Usuki, A.; Okada, A. Synthesis and properties of polyimide-clay hybrid films. J. Polym. Sci. Part. A Polym. Chem. 1997, 35, 2289-2294. [CrossRef]

30. Bharadwaj, R.; Mehrabi, A.; Hamilton, C.; Trujillo, C.; Murga, M.; Fan, R.; Chavira, A.; Thompson, A. Structure-property relationships in cross-linked polyester-clay nanocomposites. Polymers 2002, 43, 3699-3705. [CrossRef]

31. Bolotin, K.I.; Sikes, K.J.; Jiang, Z.; Klima, M.; Fudenberg, G.; Hone, J.; Kim, P.; Stormer, H.L. Ultrahigh electron mobility in suspended graphene. Solid State Commun. 2008, 146, 351-355. [CrossRef]

32. Bunch, J.S.; Verbridge, S.S.; Alden, J.S.; Van Der Zande, A.M.; Parpia, J.M.; Craighead, H.G.; McEuen, P.L. Impermeable Atomic Membranes from Graphene Sheets. Nano Lett. 2008, 8, 2458-2462. [CrossRef] [PubMed]

33. Kim, H.; Abdala, A.; Macosko, C.; Mukhopadhyay, P.; Gupta, R. Graphene/Polymer Nanocomposites. Graphi. Graphe. Polymer Nanocomp. 2012, 513-556. [CrossRef]

34. Zagho, M.M.; Al, M.; Almaadeed, A. Mechanical properties of gamma irradiated $\mathrm{TiO}_{2} \mathrm{NPs}_{\mathrm{MWCNTs} / \mathrm{MDPE}}$ hybrid nanocomposites. Emergent Mater. 2020. [CrossRef]

35. Akpan, E.; Shen, X.; Wetzel, B.; Friedrich, K. Design and Synthesis of Polymer Nanocomposites; Elsevier BV: Berlin, Germany, 2019; pp. 47-83.

36. Thomas, S.; Stephen, R. Rubber Nanocomposites: Preparation, Properties, and Applications; Wiley: Hoboken, NJ, USA, 2009.

37. Bhattacharya, M. Polymer Nanocomposites-A Comparison between Carbon Nanotubes, Graphene, and Clay as Nanofillers. Materials 2016, 9, 262. [CrossRef]

38. Pötschke, P.; Arnaldo, M.H.; Radusch, H.J. Percolation behavior and mechanical properties of polycarbonate composites filled with carbon black/carbon nanotube systems. Polimery/Polymers 2012, 57, 204-211.

39. Huang, J.-C. Carbon black filled conducting polymers and polymer blends. Adv. Polym. Technol. 2002, 21, 299-313. [CrossRef] 
40. De Oliveira, A.D.; Beatrice, C.A.G. Polymer Nanocomposites with Different Types of Nanofiller. In Nanocomposites Recent Evolutions; IntechOpen: London, UK, 2019; Volume 6, pp. 103-128.

41. Passador, F.; Ruvolo-Filho, A.; Pessan, L. Nanocomposites of Polymer Matrices and Lamellar Clays. Nanostructures 2017, 187-207. [CrossRef]

42. Naz, A.; Kausar, A.; Siddiq, M.; Choudhary, M.A. A Comparative Review on Structure, Properties, Fabrication Techniques and Relevance of Polymer Nanocomposites Reinforced with Carbon Nanotube and Graphite Fillers. Polym. Technol. Eng. 2015, 55, 171-198. [CrossRef]

43. Cong, H.; Radosz, M.; Towler, B.; Shen, Y. Polymer-inorganic nanocomposite membranes for gas separation. Sep. Purif. Technol. 2007, 55, 281-291. [CrossRef]

44. Kango, S.; Kalia, S.; Celli, A.; Njuguna, J.; Habibi, Y.; Kumar, R. Surface modification of inorganic nanoparticles for development of organic-inorganic nanocomposites-A review. Prog. Polym. Sci. 2013, 38, 1232-1261. [CrossRef]

45. Deka, B.K.; Maji, T.K. Effect of $\mathrm{TiO}_{2}$ and nanoclay on the properties of wood polymer nanocomposite. Compos. Part. A Appl. Sci. Manuf. 2011, 42, 2117-2125. [CrossRef]

46. Deka, B.K.; Maji, T.K. Effect of $\mathrm{SiO}_{2}$ and nanoclay on the properties of wood polymer nanocomposite. Polym. Bull. 2012, 70, 403-417. [CrossRef]

47. Li, Q.; Kim, J.W.; Shim, T.H.; Jang, Y.K.; Lee, J.H. Positive Temperature Coefficient Behavior of the Graphite Nanofibre and Carbon Black Filled High-Density Polyethylene Hybrid Composites. Adv. Mater. Res. 2008, 47, 226-229. [CrossRef]

48. Lee, J.H.; Kim, S.K.; Kim, N.H. Effects of the addition of multi-walled carbon nanotubes on the positive temperature coefficient characteristics of carbon-black-filled high-density polyethylene nanocomposites. Scr. Mater. 2006, 55, 1119-1122. [CrossRef]

49. Mallakpour, S.; Naghdi, M. Polymer/SiO 2 nanocomposites: Production and applications. Prog. Mater. Sci. 2018, 97, 409-447. [CrossRef]

50. Rong, M.Z.; Zhang, M.Q.; Ruan, W.H. Surface modification of nanoscale fillers for improving properties of polymer nanocomposites: A review. Mater. Sci. Technol. 2006, 22, 787-796. [CrossRef]

51. Dong, Q.; Ding, Y.; Wen, B.; Wang, F.; Dong, H.; Zhang, S.; Wang, T.; Yang, M. Improvement of thermal stability of polypropylene using DOPO-immobilized silica nanoparticles. Colloid Polym. Sci. 2012, 290, 1371-1380. [CrossRef] [PubMed]

52. Garcia, M.; van Vliet, G.; Jain, S.; Schrauwen, B.A.; Sarkissov, A.; van Zyl, W.E.; Boukamp, B.A. Polypropylene / $\mathrm{SiO} 2$ nanocomposites with improved mechanical properties. Rev. Adv. Mater. Sci. 2004, 6, 169-175.

53. Lin, O.H.; Akil, H.M.; Ishak, Z.M. Surface-activated nanosilica treated with silane coupling agents/polypropylene composites: Mechanical, morphological, and thermal studies. Polym. Compos. 2011, 32, 1568-1583. [CrossRef]

54. Grala, M.; Bartczak, Z.; Różański, A. Morphology, thermal and mechanical properties of polypropylene/SiO2 nanocomposites obtained by reactive blending. J. Polym. Res. 2016, 23, 1-19. [CrossRef]

55. Etienne, S.; Becker, C.H.; Ruch, D.; Grignard, B.; Cartigny, G.; Detrembleur, C.; Calberg, C.; Jerome, R. Effects of incorporation of modified silica nanoparticles on the mechanical and thermal properties of PMMA. J. Therm. Anal. Calorim. 2007, 87, 101-104. [CrossRef]

56. Tanahashi, M. Development of Fabrication Methods of Filler/Polymer Nanocomposites: With Focus on Simple Melt-Compounding-Based Approach without Surface Modification of Nanofillers. Materials 2010, 3, 1593-1619. [CrossRef]

57. Zubkiewicz, A.; Szymczyk, A.; Paszkiewicz, S.; Jędrzejewski, R.; Piesowicz, E.; Siemiński, J. Ethylene vinyl acetate copolymer/halloysite nanotubes nanocomposites with enhanced mechanical and thermal properties. J. Appl. Polym. Sci. 2020, 137, 49135. [CrossRef]

58. Zubkiewicz, A.; Szymczyk, A.; Franciszczak, P.; Kochmanska, A.; Janowska, I.; Paszkiewicz, S. Comparing Multi-Walled Carbon Nanotubes and Halloysite Nanotubes as Reinforcements in EVA Nanocomposites. Materials 2020, 13, 3809. [CrossRef]

59. Sun, S.; Li, C.; Zhang, L.; Du, H.; Burnell-Gray, J. Effects of surface modification of fumed silica on interfacial structures and mechanical properties of poly(vinyl chloride) composites. Eur. Polym. J. 2006, 42, 1643-1652. [CrossRef]

60. Chau, J.L.H.; Hsu, S.L.-C.; Chen, Y.-M.; Yang, C.-C.; Hsu, P.C. A simple route towards polycarbonate-silica nanocomposite. Adv. Powder Technol. 2010, 21, 341-343. [CrossRef] 
61. Oliveira, A.D.; Larocca, N.M.; Paul, D.R.; Pessan, L.A. Effects of mixing protocol on the performance of nanocomposites based on polyamide 6/acrylonitrile-butadiene-styrene blends. Polym. Eng. Sci. 2012, 52, 1909-1919. [CrossRef]

62. Paszkiewicz, S.; Szymczyk, A.; Pawlikowska, D.; Subocz, J.; Zenker, M.; Masztak, R. Electrically and Thermally Conductive Low Density Polyethylene-Based Nanocomposites Reinforced by MWCNT or Hybrid MWCNT/Graphene Nanoplatelets with Improved Thermo-Oxidative Stability. Nanomaterials 2018, 8, 264. [CrossRef] [PubMed]

63. Zagho, M.M.; Almaadeed, M.A.; Majeed, K. Thermal Properties of $\mathrm{TiO}_{2} \mathrm{NP} / \mathrm{CNT} / \mathrm{LDPE}$ Hybrid Nanocomposite Films. Polymers 2018, 10, 1270. [CrossRef] [PubMed]

64. Paszkiewicz, S.; Szymczyk, A.; Zubkiewicz, A.; Subocz, J.; Stanik, R.; Szczepaniak, J. Enhanced Functional Properties of Low-Density Polyethylene Nanocomposites Containing Hybrid Fillers of Multi-Walled Carbon Nanotubes and Nano Carbon Black. Polymers 2020, 12, 1356. [CrossRef]

65. Badgayan, N.D.; Sahu, S.K.; Samanta, S.; Sreekanth, P.R. Assessment of nanoscopic dynamic mechanical properties and B-C-N triad effect on MWCNT/h-BNNP nanofillers reinforced HDPE hybrid composite using oscillatory nanoindentation: An insight into medical applications. J. Mech. Behav. Biomed. Mater. 2018, 80, 180-188. [CrossRef]

66. Mekhzoum, M.E.M.; Essabir, H.; Rodrigue, D.; Qaiss, A.E.K.; Bouhfid, R. Graphene/montmorillonite hybrid nanocomposites based on polypropylene: Morphological, mechanical, and rheological properties. Polym. Compos. 2016, 39, 2046-2053. [CrossRef]

67. Franciszczak, P.; Taraghi, I.; Paszkiewicz, S.; Burzynski, M.; Piesowicz, E. Polypropylene Reinforced with Short Kenaf Fibers and Halloysite Nanoclay: Mechanical properties, Thermal stability and Morphology of Manufactured Hybrid Biocomposites. Materials 2020, 13, 4459. [CrossRef]

68. Sánchez-Valdés, S. Influence of maleated elastomer on filler dispersion, mechanical and antimicrobial properties of hybrid HDPE/clay/silver nanocomposites. J. Adhes. Sci. Technol. 2016, 30, 1006-1016. [CrossRef]

69. Dabees, S.; Ahmed, B.; Sanad, M.; Elsshalakny, A.B. Experimental Design of AL2O3/MWCNT/HDPE Hybrid Nanocomposites for Hip Joint Replacement. Res. Sq. 2020, 11, 1-19. [CrossRef]

70. Aguilar, H.; Yazdani-Pedram, M.; Toro, P.; Quijada, R.; López-Manchado, M.Á. Synergic Effect of Two Inorganic Fillers on the Mechanical and Thermal Properties of Hybrid Polypropylene Composites. J. Chil. Chem. Soc. 2014, 59, 2468-2473. [CrossRef]

71. Pandey, P.; Mohanty, S.; Nayak, S.K. Hybrid Effect of Nanosilicates and MWNT on Mechanical, Thermal, and Dynamic Mechanical Properties of Polypropylene. Chin. J. Eng. 2014, 2014, 1-8. [CrossRef]

72. Mohammadi, H.; Moghbeli, M.R. Polypropylene/organically modified-grafted mica/organoclay hybrid nanocomposites: Preparation, characterization, and mechanical properties. Polym. Compos. 2018, 40, 1718-1730. [CrossRef]

73. Majeed, K.; Ahmed, A.; Abu Bakar, M.S.; Mahlia, T.M.I.; Saba, N.; Hassan, A.; Jawaid, M.; Hussain, M.; Iqbal, J.; Ali, Z. Mechanical and Thermal Properties of Montmorillonite-Reinforced Polypropylene/Rice Husk Hybrid Nanocomposites. Polymers 2019, 11, 1557. [CrossRef]

74. Rahman, M.; Rahman, R.; Hamdan, S.; Hossen, F. Effect of Silicon Dioxide/Nanoclay on the Properties of Jute Fiber/Polyethylene Biocomposites. J. Vinyl Addit. Technol. 2015, 23, E107-E112. [CrossRef]

75. Xu, J.-Z.; Zhong, G.-J.; Hsiao, B.S.; Fu, Q.; Li, Z.-M. Low-dimensional carbonaceous nanofiller induced polymer crystallization. Prog. Polym. Sci. 2014, 39, 555-593. [CrossRef]

76. Khandelwal, N.; Kaur, G.; Kumar, N.; Tiwari, A. Application of silver nanoparticles in viral inhibition: A new hope for antivirals. Dig. J. Nanomater. Biostruct. 2014, 9, 175-186.

77. Badgayan, N.D.; Samanta, S.; Sahu, S.K.; Siva, S.B.V.; Sadasivuni, K.K.; Sahu, D.; Sreekanth, P.S.R. Tribological behaviour of 1D and 2D nanofiller based high density poly-ethylene hybrid nanocomposites: A run-in and steady state phase analysis. Wear 2017, 376-377, 1379-1390. [CrossRef]

Publisher's Note: MDPI stays neutral with regard to jurisdictional claims in published maps and institutional affiliations. 